\title{
The Relationship between Pulmonary Function Testing Including Cardiopulmonary Exercise Testing (CPET) and Outcomes in Patients with Oesophagogastric Cancer Undergoing Neo-adjuvant Chemotherapy
}

\author{
Dr. Janan Alrefaee ${ }^{a}$, Professor Donald C McMillan ${ }^{b}$, Dr. Roger Carter ${ }^{c}$, Dr. Jane E. Nally ${ }^{d}$ \\ ${ }^{a}$ Department of Medical Physiology, College of Medicine, University of Mosul, Mosul, Iraq, ${ }^{b}$ University of Department of

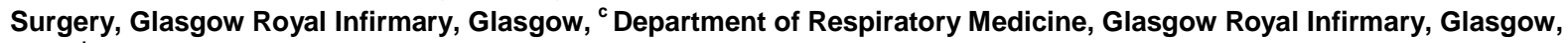 \\ ${ }^{\mathrm{d}}$ School of Health and Life Sciences, Department of Life Sciences, Glasgow Caledonian University, Glasgow. \\ Correspondence: Janan Alrefaee. janan1969@yahoo.com.
}

(Ann Coll Med Mosul 2019; 41 (1):43-51).

Received: $4^{\text {th }}$ Oct. 2018; Accepted: $20^{\text {th }}$ Jan. 2019.

\begin{abstract}
Background: In the field of gastro-oesophageal cancer, the effect of chemotherapy treatment on patients' cardiopulmonary fitness as well as on the incidence of post-operative cardiopulmonary complications remains controversial.

Objectives: To examine the effect of chemotherapy on cardiopulmonary fitness. Further, to examine the association between cardiopulmonary exercise testing and other measurements on outcomes in patients with gastro-oesophageal cancer undergoing neo-adjuvant chemotherapy. And to compare post chemotherapy cardiopulmonary exercise testing with surgical outcome.

Patients and methods: Forty-one patients with gastroesophageal cancer who underwent chemotherapy were referred to the Pulmonary Function Laboratory, Respiratory Medicine, Glasgow Royal Infirmary during the period August 2008 to December 2011. 35 of these patients underwent both pre- and post-chemotherapy pulmonary function testing and 31 of these 35 patients had their chemotherapy followed by surgery.

A further 6 patients underwent chemotherapy followed by pulmonary function testing and surgery but without pre-chemotherapy testing

Results: There were significant differences between the pre- and post-chemotherapy results in arterial PCO2 $(p<0.01)$, t hemoglobin $(p<0.001)$ and heart rate at anaerobic threshold as a $\%$ of maximum predicted heart rate $(p<0.05)$. There were significant differences between those patients without post-operative complications and those with post-operative complications, in length of high dependency care stay $(p<0.01)$, length of ward stay $(p<0.05)$ and length of hospital stay $(p<0.001)$

Conclusion: the results of the present study show that there was no significant change in cardiopulmonary fitness in patients with gastro-oesophageal cancer who underwent chemotherapy apart from correctable side effect such as anaemia. In addition, CPET parameters, pulmonary function tests and other related factors did not predict an increase in the risk of post-operative complications. There was, however, a relationship between deprivation and an increased risk of postoperative complications.
\end{abstract}

Keywords: Cardiopulmonary exercise testing, Chemotherapy, Anaerobic threshold, Respiratory, Risk.

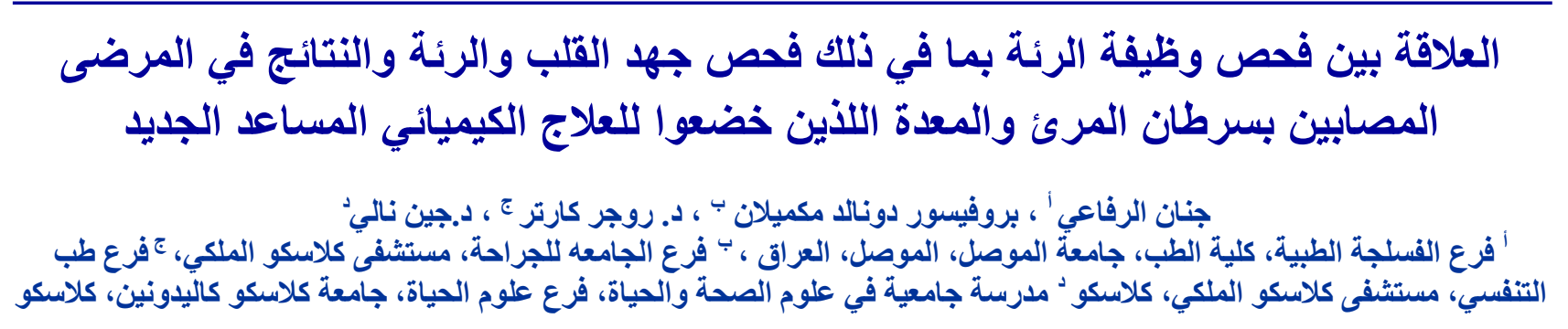


الخلفية: تأثثير العلاج الكيميائي على لياقة قلب ورئة المريض المصاب بسرطان المعدة و المرىئ و أيضا على حدوث مضاعفات

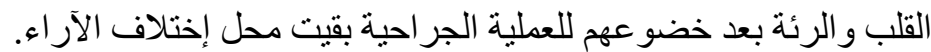

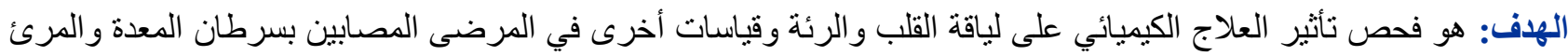

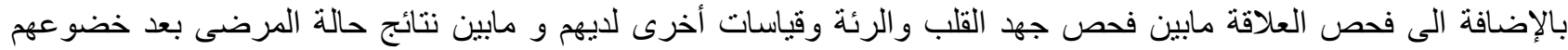
اللعملية الجر احية.

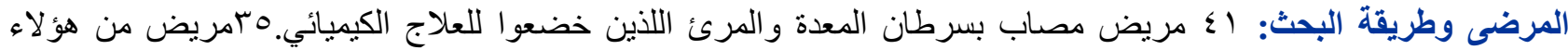

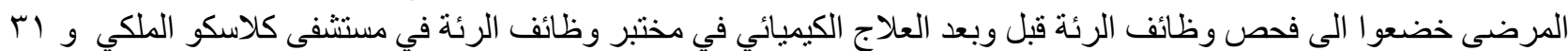

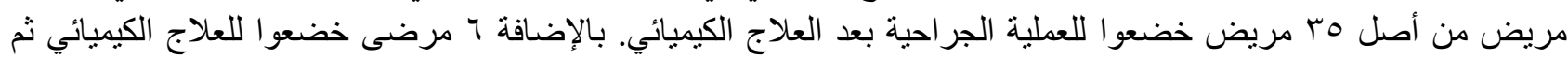

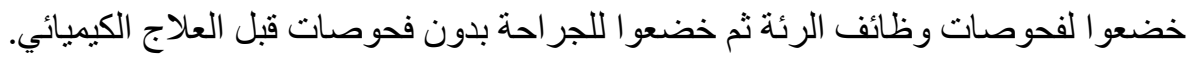

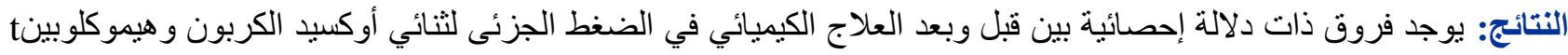

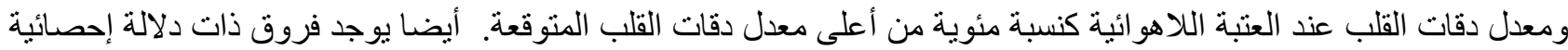

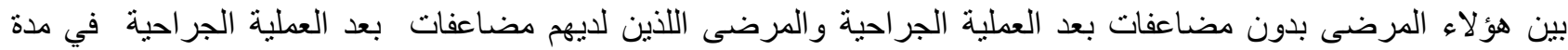

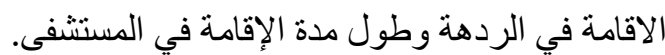

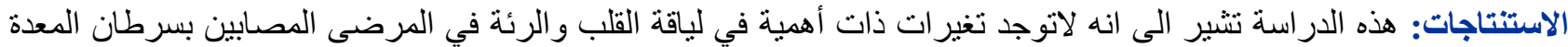

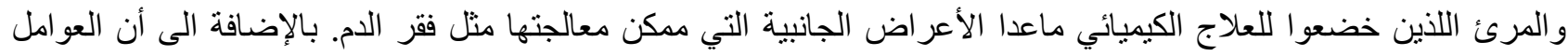

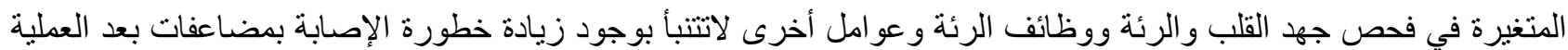

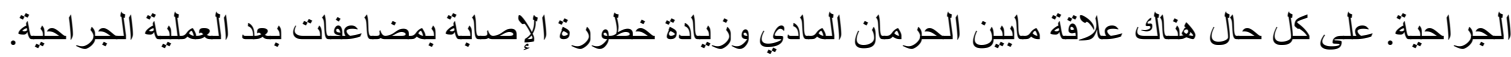

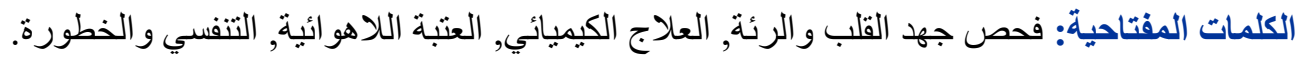

\section{INTRODUCTION}

$\mathrm{T}$ he majority of cancer patients suffer from symptoms as a consequence of both their disease and its treatment. Neo-adjuvant chemotherapy has been recommended in the treatment of upper gastrointestinal malignancy in an attempt to downstage tumour activity in order to enhance respectability, as a precaution to destroy any micro-metastasis foci of the malignancy and to improve symptoms and survival. ${ }^{1,2}$ It has, however, been shown that neo-adjuvant chemotherapy is complicated by toxicity and illness related to treatment e.g. neutropaenia and anaemia leading to an increased risk of mortality. ${ }^{2}$

There is continuing controversy about the advantage of using neo-adjuvant chemotherapy in cancer treatment. ${ }^{1}$ In the respiratory field, studies suggest that neo-adjuvant chemotherapy increases the risk of respiratory complications after pneumonectomy ${ }^{3}$ and it has been recommended that carbon monoxide transfer factor (TLCO) be assessed in lung cancer patients before and after chemotherapy induction since TLCO is a sensitive risk indicator of respiratory complications after surgery. ${ }^{3}$ Conversely, it has been found that pre- operative chemotherapy did not impact on postoperative morbidity and mortality in lung cancer patients. ${ }^{4}$ Furthermorean upgrading in lung function and exercise capacity was noted after chemotherapy initiation in patients with malignant pleural mesothelioma ${ }^{5}$, although this study was without post-chemotherapy surgery.

In the gastro-oesophageal field, some studies suggest that there is no additional benefit of chemotherapy in the treatment of oesophageal cancer as there is no variation in anastomotic leaks, pulmonary or cardiac complications with pre-operative chemotherapy compared to surgery alone. ${ }^{6,7,8}$ In addition, there is evidence of toxicity and pre-operative mortality related to chemotherapy in patients with oesophageal cancer, who underwent neo-adjuvant chemotherapy ${ }^{9}$ and the post-oesophagectomy complication incidence is higher in those patients who had higher pre-operative chemotherapy toxicities. ${ }^{10}$ By contrast, other studies showed that chemotherapy improves survival for gastrooesophageal cancer. ${ }^{2,11,12}$ It has been found that reduction of pre-operative and especially post- 
operative oncological treatment toxicity is essential for the ongoing improvement of gastric cancer care. $^{13}$ There was no apparent cause for the difference in results between these studies since they had the same location of cancer (e.g oesophageal cancer) or similar histology of cancer (e.g. gastric cancer is histologically similar to oesophagus cancer).

Accordingly in the field of gastro-oesophageal cancer, the effect of chemotherapy treatment on patients' cardiopulmonary fitness as well as on the incidence of post-operative cardiopulmonary complication remains controversial.

\section{Aims of the study}

The aim of the present study was to examine the effect of chemotherapy on cardiopulmonary fitness. In addition we have examined the association between pulmonary function measurements including CPET and outcomes in patients with gastro-oesophageal cancer undergoing neo-adjuvant chemotherapy. And to compare post chemotherapy CPET with surgical outcome.

\section{PATIENTS}

This is a case-control study. 41 Patients who were included in this study had been diagnosed with gastro-oesophageal cancer proven histologically by the Pathology laboratory, Glasgow Royal Infirmary. All patients were referred to the Pulmonary Function Laboratory, Respiratory Medicine, Glasgow Royal Infirmary between August 2008 and December 2011. These patients underwent chemotherapy as described below.

- 35 of the patients with gastro-oesophageal cancer underwent both pre- and postchemotherapy CPET (this group was analysed to assess the effect of chemotherapy on cardiopulmonary fitness). 31 out of these 35 patients underwent pre- and postchemotherapy CPET, followed by surgery.

- A further 6 patients with gastro-oesophageal cancer underwent chemotherapy followed by CPET and surgery but without a prechemotherapy CPET. In total, 37 patients underwent chemotherapy followed by a postchemotherapy CPET and surgery (this group was analysed to compare post chemotherapy CPET with surgical outcome).

\section{METHODS}

The Neo-adjuvant chemotherapy study protocol is started by diagnosis followed by first CPET followed by neo-adjuvant chemotherapy followed by second CPET followed by surgery followed by post -operative outcome follow up

The regional multidisciplinary team referred the diagnosed patients for lung function testing and CPET in order to plan their treatment.

At the pulmonary laboratory, all tests including anthropometric measurements, capillary blood sampling from ear (gas analysis and $\mathrm{tHb}$ ) and the patients' deprivation levels were determined by using the Scottish index of multiple deprivations (SIMD) 2012 calculator. Then flow-volume loop, transfer factor for carbon monoxide test (TLCO) and the cardiopulmonary exercise test (CPET) were performed \{Peak VO2 (Oxygen consumption) and VO2 at anaerobic threshold (AT), Absolute AT and other CPET results as mentioned in Table 2\}. CPET was conducted by using a metabolic exercise cart on an electrically braked bicycle ergometer. Flow and gas calibration were performed manually before CPET. Electronic sphygmomanometer and 12- electrocardiogram electrodes were connected to the patient and the CPET method protocol as following:

- 3 minute rest (breathing flow \& concentration analysis + ECG monitor)

- 1 minute unloaded cycling 50-60 rpm (breathing flow \& concentration analysis + ECG

- Cycling 50-60 rpm with 10-20 watt/minute incremental load until symptom limiting the test or exhaustion

- Recovery period (2-10 minutes) unloaded cycling

ECG, Heart rate, respiratory exchange ratio and pulse oximetry were monitored and blood pressure was measured automatically every 2 minutes using sphygmomanometer. ${ }^{14,15}$

The test was ended before the patient reached exhaustion level if the patient signed that they had either chest pain or difficulty in breathing. The test was also stopped if there was depression or elevation of ST segment $\geq 2 \mathrm{~mm}$, T wave inversion or sustained ventricular tachycardia. ${ }^{16,17,18}$

Anaerobic threshold determination was by the Vslope method ${ }^{18,19,20}$ which was confirmed by ventilatory equivalent, end tidal partial pressure 
methods ${ }^{18,20}$ and respiratory exchange ratio (RER) changes. ${ }^{21}$ These methods were observed initially by using $8-$ panel and then confirmed by 9 -panel and 4-panel graph plots.

The regional multidisciplinary team meeting decided that these patients either had an operable tumour but needed to be treated by chemotherapy before operation or these patients had an inoperable tumour and needed to be treated by chemotherapy treatment alone. The patients were referred to the Oncologist at the Beatson West of Scotland Cancer Centre, Glasgow for chemotherapy. The following chemotherapeutic regimens were used by the oncologists to treat gastroesophageal, gastric cancers (the only first 3 regimens) and oesophageal cancer (all regimens), are:

- Epirubicin plus Cisplatin plus 5-FU called ECF..............or

- Epirubicin plus Cisplatin plus Capecitabine called ECX......or

- Epirubicin plus Oxaliplatin plus 5-FU called EOF. ..or

- Cisplatin plus 5-FU called CF

Patients who had operable oesophageal or oesophagogastric cancer received two to three cycles of one of the chemotherapy regimens described. Operable gastric cancers patients were treated with three cycles of one regimen. While inoperable gastro-oesophageal cancers were treated by different numbers of chemotherapeutic cycles. The courses of chemotherapy drugs were given at three-week intervals. After completion of chemotherapy treatment, the team referred patients to undergo CT scan to assess disease progression.

Patients who were being considered for surgery were referred back to the Pulmonary Function Laboratory, Respiratory Medicine, Glasgow Royal Infirmary to reassess their lung function and perform post-chemotherapy testing. These patients then underwent surgical resection in the form of transhiatal oesophagectomy, partial or subtotal gastrectomy and gastro-oesophagectomy depending on their disease location. One case only underwent palliative (Roux limb) gastroenterostomy.

Post-surgery the patients were admitted to the High Dependency Unit (HDU) or Intensive Care
Unit (ICU) depending on patient's general health. When patients improved, they were transferred to a general surgical ward. Both the length of the high dependency unit stay and the intensive care stay were merged in this study under title of length of high dependency care stay.

Patients were followed up for the first 30 days post-surgery and information about neo-adjuvant chemotherapy as well as the post-operative outcomes and complications that were recorded are illustrated in Table 1.

Table 1: Post-operative outcomes and related information in patients that underwent chemotherapy.

\begin{tabular}{|c|c|}
\hline $\begin{array}{l}\text { Types of } \\
\text { post- } \\
\text { operative } \\
\text { outcomes }\end{array}$ & Information and complications \\
\hline $\begin{array}{l}\text { Cardiac } \\
\text { complication } \\
\text { in } 1^{\text {st }} 30 \text { days } \\
\text { post-operative }\end{array}$ & $\begin{array}{l}\text { Presence, number and type of cardiac } \\
\text { complications }\end{array}$ \\
\hline $\begin{array}{l}\text { Pulmonary } \\
\text { complication } \\
\text { in } 1^{\text {st }} 30 \text { days } \\
\text { post-operative }\end{array}$ & $\begin{array}{l}\text { Presence, number and type of } \\
\text { pulmonary complications }\end{array}$ \\
\hline $\begin{array}{l}\text { Anastomotic } \\
\text { leakage }\end{array}$ & Presence of post-operative leak \\
\hline $\begin{array}{l}\text { Wound } \\
\text { infection }\end{array}$ & $\begin{array}{l}1^{\text {st }} \text { post-operative } 30 \text { days wound } \\
\text { infection }\end{array}$ \\
\hline Mortality & $\begin{array}{l}\text { 1st post-operative } 30 \text { days mortality } \\
\text { After } 1^{\text {st }} \text { post-operative } 30 \text { days mortality }\end{array}$ \\
\hline $\begin{array}{l}\text { Intensive care } \\
\text { unit (ICU) }\end{array}$ & $\begin{array}{l}\text { Length of ICU stay (days) } \\
\text { Number of ICU admissions in } 1^{\text {st }} 30 \text { days } \\
\text { or post-operative in hospital stay }\end{array}$ \\
\hline $\begin{array}{l}\text { High } \\
\text { dependency } \\
\text { unit HDU) }\end{array}$ & $\begin{array}{l}\text { Length of HDU stay (days) } \\
\text { Number of HDU admissions in } 1^{\text {st }} 30 \\
\text { days or postoperative in hospital stay }\end{array}$ \\
\hline Ward stay & Length of ward stay (days) \\
\hline $\begin{array}{l}\text { Length of } \\
\text { hospital stay }\end{array}$ & $\begin{array}{l}\text { Length of hospital stay (days) } \\
\text { Number of hospital admissions in } 1^{\text {st }} 30 \\
\text { days }\end{array}$ \\
\hline $\begin{array}{l}\text { Medical } \\
\text { history }\end{array}$ & Past medical and drug history \\
\hline $\begin{array}{l}\text { Chemotherapy } \\
\text { treatment }\end{array}$ & $\begin{array}{l}\text { Type of chemotherapy regimen } \\
\text { The duration between } 1^{\text {st }} \text { CPET and } \\
\text { commencing chemotherapy treatment } \\
\text { Number and duration of chemotherapy } \\
\text { cycles } \\
\text { Duration between the date of completing } \\
\text { chemotherapy and } 2^{\text {nd }} \text { CPET } \\
\text { Duration between } 2^{\text {nd }} \text { CPET and } \\
\text { operation } \\
\text { Duration between } \\
\text { chemotherapy and operation } \\
\text { Duration between } 1^{\text {st }} \text { CPET and death }\end{array}$ \\
\hline
\end{tabular}


Statistical analysis

The study data are presented as numbers and percentage or medians and ranges. Comparison of patient groups was carried out using nonparametric (Wilcoxon), parametric (paired samples test); a Mann-Whitney and chi square test and Pearson or Spearman as appropriate using SPSS software (IBM, SPSS, Version 19.0, USA), $P \leq 0.05$ was considered significant.

\section{RESULTS}

For the 35 patients with gastro-oesophageal cancer who underwent pre- and postchemotherapy CPET, the results are shown in Table (2).

Median of carboxyhaemoglobin \% (carbox- $\mathrm{Hb} \%$ ) was higher than normal range in both the pre- and post-chemotherapy groups. Absolute peak $\mathrm{VO}_{2}$, peak $\mathrm{VO}_{2} \%$ predicted maximum $\mathrm{VO}_{2}$, absolute AT and $\mathrm{AT} \%$ predicted maximum $\mathrm{VO}_{2}$ medians were lower than the normal range in both groups. A test of normality was done for each parameter.

There were significant differences between both pre- and post-chemotherapy groups in arterial $\mathrm{PCO}_{2}$ (4.5 vs. 4.7, respectively; $p<0.01$ ), t $\mathrm{Hb}$ (15 vs. 13 , respectively; $p<0.001)$ and heart rate at $A T$ $\%$ maximum predicted HR (67 vs. 71 , respectively; $\mathrm{p}<0.05)$. There were no significant differences in other variables.

The 37 patients that underwent a $2^{\text {nd }}$ CPET (post-chemotherapy) followed by surgery were categorised depending on the development of post-operative complications into 11 (30\%) patients with no post-operative complications and 26 (70\%) patients with post-operative complications. The clinic-pathological characteristic indices, CPET parameters and postoperative complications are shown in Table 3 (This analysis did not include smoking status due to insufficient data).

Median of body mass index (BMI) and carbox$\mathrm{Hb} \%$ were above the normal range in both groups. Absolute peak $\mathrm{VO}_{2}$, peak $\mathrm{VO}_{2} \%$ predicted maximum $\mathrm{VO}_{2}$, and absolute AT medians were lower than the normal range in both groups. AT \% predicted maximum $\mathrm{VO}_{2}$ was within normal range in the group without post-operative complications group while it was lower than normal in the group that had post-operative complications. All other variables were within normal range.

Table 2: The effect of chemotherapy on CPET and other related parameters in gastro-oesophageal cancer patients.

\begin{tabular}{|c|c|c|c|c|}
\hline $\begin{array}{l}\text { Investigation } \\
\text { parameters }\end{array}$ & $\begin{array}{l}\text { Normal } \\
\text { range }\end{array}$ & $\begin{array}{l}\text { Pre-chemotherapy } \\
(n=35)\end{array}$ & $\begin{array}{l}\text { Post-chemotherapy } \\
(n=35)\end{array}$ & $\begin{array}{c}p- \\
\text { value }\end{array}$ \\
\hline Arterial $\mathrm{PCO}_{2}(\mathrm{kPa})$ & $4.5-6.0$ & $4.5(3.7-5.1)$ & $4.7(3.4-5.7)$ & 0.008 \\
\hline $\mathrm{t} \mathrm{Hb}(\mathrm{g} / \mathrm{dl})$ & $12-16$ & $15(9-17)$ & $13(11-15)$ & $<0.001$ \\
\hline Carbox-Hb (\%) & $0.3-1.0$ & $1.8(1.1-11.9)$ & $2.7(1.0-8.0)$ & 0.290 \\
\hline FVC (\%predicted ) & $>75$ & $107(87-158)$ & $109(55-154)$ & 0.078 \\
\hline FEV1/FVC (\%Predicted) & $>75$ & $95(61-112)$ & $96(63-128)$ & 0.517 \\
\hline Peak $\mathrm{VO}_{2}$ (absolute) & $35-40$ & $16.5(8.0-33.3)$ & $16.5(8.6-36.9)$ & 0.330 \\
\hline Peak $\mathrm{VO}_{2}\left(\%\right.$ predicted Maximum $\left.\mathrm{VO}_{2}\right)$ & $>80$ & $60.2(41.5-170.5)$ & $59.7(37.4-116.0)$ & 0.552 \\
\hline Anaerobic threshold (absolute) & $15-25$ & $10.9(4.3-19.3)$ & $10.7(5.2-18.1)$ & 0.639 \\
\hline Anaerobic threshold (\%predicted maximum $\mathrm{VO}_{2}$ ) & $40-80$ & $39.1(20.1-101.2)$ & $39.5(28.9-68.1)$ & 0.643 \\
\hline $\mathrm{VE} / \mathrm{VCO}_{2}($ at $\mathrm{AT})$ & 23-34 & $27(22-46)$ & $27(22-38)$ & 0.646 \\
\hline $\mathrm{VE} / \mathrm{VO}_{2}$ (at AT) & $\leq 34$ & $26(20-44)$ & $28(22-40)$ & 0.082 \\
\hline Work efficiency (ml/kg.min) & $8.5-11$ & $9.7(7.2-12.1)$ & $9.7(5.2-11.7)$ & 0.397 \\
\hline Ventilatory reserve (\%) & $15-50$ & $45(28-74)$ & $44(26-89)$ & 0.586 \\
\hline $\mathrm{O}_{2}$ saturation difference from peak to rest (\%) & $\leq 4$ & $-1.0(-7-1)$ & $-1(-9-2)$ & 0.608 \\
\hline Peak $\mathrm{O}_{2}$ pulse (\%predicted) & & $80(48-129)$ & $78(48-115)$ & 0.188 \\
\hline $\begin{array}{l}\text { Heart rate at anaerobic threshold (\% maximum } \\
\text { predicted HR) }\end{array}$ & & $67(47-84)$ & $71(44-85)$ & 0.040 \\
\hline Heart rate at peak (\%maximum predicted HR) & & $89(58-104)$ & $88(63-108)$ & 0.089 \\
\hline $\mathrm{HR} / \mathrm{VO}_{2}$ difference from peak to $\mathrm{AT}^{*}$ & & $9(-13-35)$ & $9(-6-36)$ & 0.798 \\
\hline $\mathrm{O}_{2}$ pulse difference from peak to $\mathrm{AT}$ & & $2(0-8)$ & $2(0-8)$ & 0.512 \\
\hline
\end{tabular}

All values gives as median (range) Total patients' numbers vary due to incomplete data.SA= surface area; AT= anaerobic threshold; $\mathrm{VE}=$ ventilatory equivalent; $\mathrm{HR}=$ heart rate. ${ }^{*} \mathrm{HR} / \mathrm{VO}_{2}$ at peak minus $\mathrm{HR} / \mathrm{VO}_{2}$ at anaerobic threshold. 
There was a significant association between post-operative complications and deprivation in patients with gastro-oesophageal cancer that underwent pre-operative chemotherapy $(p<0.05)$. The patients with post-operative complications had a higher percentage of the most deprived patients and a lower percentage of the least deprived patients compared with those without postoperative complications. There were significant differences between patients without postoperative complications and those with, in length of high dependency care stay (8 vs. 11, respectively; $\mathrm{p}<0.01$ ), in length of ward stay (5 vs. 9, respectively; $p<0.05)$ and length of hospital stay (12 vs. 22 , respectively; $p<0.001$ ). There were no significant differences between groups in other variables.

Table 3: The relationship between post chemo-CPET and other investigations parameters and post-operative complications in gastro-oesophageal cancer surgery patients $(n=37)$.

\begin{tabular}{|c|c|c|c|c|}
\hline \multirow{2}{*}{ Parameters } & \multirow{2}{*}{$\begin{array}{l}\text { Normal } \\
\text { range }\end{array}$} & \multicolumn{2}{|c|}{ Post-operative complications } & \multirow[b]{2}{*}{ P-value } \\
\hline & & No $(n=11)$ & Yes $(n=26)$ & \\
\hline Age (years) & & $65(49-76)$ & $66(50-76)$ & 0.803 \\
\hline Sex (male/female): $n$ (\%) & & $7(64) / 4(36)$ & $20(83) / 4(17)$ & 0.533 \\
\hline \multicolumn{5}{|l|}{ Deprivation level: $n(\%)$} \\
\hline $\begin{array}{r}\text { Most deprivation (1) } \\
\qquad \begin{array}{r}(2) \\
(3) \\
(4) \\
\text { Least deprivation (5) }\end{array}\end{array}$ & & $\begin{array}{l}1(10) \\
1(10) \\
5(50) \\
1(10) \\
2(20)\end{array}$ & $\begin{array}{l}7(32) \\
8(37) \\
4(18) \\
1(5) \\
2(8)\end{array}$ & 0.049 \\
\hline Body mass index $\left(\mathrm{kg} / \mathrm{m}^{2}\right)$ & $18.5-25$ & $26.8(24.2-35.2)$ & $27.5(18.1-38.5)$ & 0.559 \\
\hline Arterial $\mathrm{PCO}_{2}(\mathrm{kPa})$ & $4.5-6.0$ & $4.7(3.4-5.2)$ & $4.6(4.0-5.7)$ & 0.558 \\
\hline t Hb (g/dl) & $12-16$ & $12.6(10.4-14.7)$ & $13.4(10.5-15.2)$ & 0.557 \\
\hline Carbox-Hb (\%) & $0.3-1.0$ & $1.8(1.0-6.2)$ & $2.8(1.2-8.0)$ & 0.444 \\
\hline FVC (\%predicted ) & $>75$ & $112(88-136)$ & $109(55-154)$ & 0.425 \\
\hline FEV1/FVC (\%Predicted) & $>75$ & $93(63-106)$ & $97(67-128)$ & 0.514 \\
\hline TLCO corrected for $\mathrm{Hb} \& \mathrm{SA}$ (\% predicted) & $>75$ & $88(87-106)$ & $84(53-112)$ & 0.604 \\
\hline Peak $\mathrm{VO}_{2}$ (absolute) & $35-40$ & $17.2(8.6-29.0)$ & $15.1(10.2-36.9)$ & 0.959 \\
\hline Peak $\mathrm{VO}_{2}(\%$ predicted maximum VO2) & $>80$ & $63.1(51.4-89.9)$ & $58.3(37.4-116.0)$ & 0.210 \\
\hline Anaerobic threshold (absolute) & $15-25$ & $10.1(5.2-16.3)$ & $10.6(6.3-18.1)$ & 0.907 \\
\hline $\begin{array}{l}\text { Anaerobic threshold } \\
\text { (\% predicted maximum VO2) }\end{array}$ & $40-80$ & $41.9(33.3-72.7)$ & $39.5(28.9-68.1)$ & 0.455 \\
\hline $\mathrm{VE} / \mathrm{VCO}_{2}($ at $\mathrm{AT})$ & 23-34 & $29(24-36)$ & $28(22-38)$ & 0.790 \\
\hline $\mathrm{VE} / \mathrm{VO}_{2}($ at $\mathrm{AT})$ & $\leq 34$ & $26(22-37)$ & $28(22-40)$ & 0.425 \\
\hline Work efficiency (ml/kg.min) & $8.5-11$ & $9.5(5.2-11.7)$ & $9.7(6-11.2)$ & 0.932 \\
\hline Ventilatory reserve (\%) & $15-50$ & $43(27-64)$ & $45(26-86)$ & 0.466 \\
\hline Length of high dependency care stay & & $8(3-11)$ & $11(6-57)$ & 0.002 \\
\hline Length of ward stay & & $5(1-9)$ & $9(0-32)$ & 0.010 \\
\hline Length of hospital stay & & $12(6-19)$ & $22(11-85)$ & $<0.001$ \\
\hline $\begin{array}{l}1^{\text {st }} \text { post-operative month mortality: } \\
\text { No }(\mathrm{n}(\%)) / \text { yes }(\mathrm{n}(\%))\end{array}$ & & $0(0-0)$ & $0(0-1)$ & 0.488 \\
\hline
\end{tabular}

All values given as median (range) Total patients' numbers vary due to incomplete data. SA= surface area; $\mathrm{AT}=$ anaerobic threshold; $\mathrm{VE}=$ ventilatory equivalent. Mann-Whitney $\mathrm{U}$ test \& Chi-square test. ${ }^{*}$ is the difference between $\mathrm{HR} / \mathrm{VO}_{2}$ at peak and $\mathrm{HR} / \mathrm{VO}_{2}$ at anaerobic threshold. 


\section{DISCUSSION}

The present study found no significant change in cardiopulmonary fitness in patients who underwent chemotherapy as shown by peak oxygen consumption; anaerobic threshold and resting pulmonary function. This finding is in contrast to a previous study that demonstrated an improvement in exercise capacity (peak $\mathrm{VO}_{2}$ ) and pulmonary function after induction chemotherapy in patients with malignant pleural mesothelioma. ${ }^{22}$ This difference is most probably due to to the kind of cancer. The present study is also inconsistent with a study that showed a down grading effect on pulmonary function in patients with any kind of cancer treated with chemotherapy because chemotherapy induced immune defects leading to lung infection. ${ }^{23}$ This difference may be due to the small sample size in the present study which did find that there was an increase in arterial $\mathrm{PCO}_{2}$ in patients treated by chemotherapy, but it was still near the lower limit of normal range.

It was observed, however, that there was a risk of anaemia post-chemotherapy due to a decrease in haemoglobin concentration. This finding is supported by other studies that reported anaemia to be a consequence of chemotherapy. ${ }^{24,25}$ As much as anaemia is an important complication, it is treatable by red blood cell transfusion. ${ }^{26}$ This anaemia would also explain the increase in heart rate at anaerobic threshold in patients who underwent chemotherapy. ${ }^{27}$

The results of present study showed that CPET, pulmonary function testing and related factors were not associated with the development of postoperative complications in patients who underwent neo-adjuvant chemotherapy. This finding is consistent with a previous study that concluded that pre-operative chemotherapy does not increase the risk of complications, in particular pulmonary complications, or hospital mortality post advanced thoracic oesophageal cancer surgery. ${ }^{28,29,30}$ It is, however, in contrast to a study that reported that pulmonary function test parameters predict postoperative complication in patients with oesophageal cancer undergoing chemoradiotherapy. ${ }^{31}$ This difference is most probably due to the difference in the type of oncological treatment (chemo-radiotherapy) and to the type of surgery (only oesophagectomy), compared with this study which only used chemotherapy and looked at patients that underwent gastrooesophageal surgeries. A further study found that the risk of respiratory complications after pneumonectomy is increased in the case of induction chemotherapy ${ }^{32}$ in contrast to our findings. This difference may be due to the type of surgery - pneumonectomy - and larger sample size (99 patients).

Perhaps not surprisingly, patients who developed postoperative complications had a longer high dependency care stay, ward stay and hospital stay than those who did not develop post-operative complications.

The present study showed that patients living in highly deprived areas were more liable to develop postoperative complications than those living in less deprived areas. This finding is consistent with the work of Taylor who showed that deprivation is an independent predictor of poor cardiovascular an outcome in a British population undergoing coronary artery bypass grafting and that upper gastrointestinal cancer treated by chemoradiotherapy or radiotherapy occurred more in patients living in a most deprived area compared to those living in a least deprived area. ${ }^{33}$ It may be that patients in deprived areas are less likely to report symptoms early leading to a complicated and metastatic cancer. Similarly it has been shown that patients with colorectal, lung, and breast cancer living in deprived areas are more likely to be admitted as emergencies or as inpatient admissions and less likely to be admitted as day cases in south east England. ${ }^{34}$

\section{CONCLUSION}

In summary, the results of the present study show that there was no significant change in cardiopulmonary fitness in patients with gastrooesophageal cancer who underwent chemotherapy except side effects, for example anaemia, that could be treated. In addition, CPET parameters, pulmonary function tests and other related factors did not predict an increase in the risk of post-operative complications in patients with gastro-oesophageal cancer who underwent neoadjuvant chemotherapy. Although the patient numbers in this study are small, the effect of chemotherapy on cardiopulmonary fitness has not previously been well studied and thus the data from this limited number of patients is useful. 
This study showed that deprivation is an independent predictor of postoperative complications.

\section{REFERENCES}

1. Chong G, Cunningham D. Oesophageal cancer: Preoperative chemotherapy. Annals of Oncology 2004; 15 (Supplement 4): iv87-iv91.

2. Malthaner R , Fenlon D. Preoperative chemotherapy for resectable thoracic esophageal cancer (review). The Cochrane Collaboration 2006; (CD001556), issue 4.

3. Leo F, Solli P, Veronesi G, Radice D, Floridi A, Gasparri $R$, et al. Does chemotherapy increase the risk of respiratorycomplications after pneumonectomy?. J Thorac Cardiovasc Surg 2006; 132: 519-23.

4. Siegenthaler MP, Pisters KM, Merriman KW, Roth JA, Swisher SG, Walsh GL, et al. Preoperative chemotherapy for lung cancer does not increase surgical morbidity. Ann Thorac Surg 2001; 71: 1105-12.

5. Marulli G, Rea F, Nicotra S, Favaretto AG, Perissinotto $\mathrm{E}$, Chizzolini $\mathrm{M}$, et al. Effect of induction chemotherapy on lung function and exercise capacity in patients affected by malignant pleural mesothelioma. European Journal of Cardio-Thoracic Surgery 2010; 37(6): 1464-1469.

6. Bhansali M, Vaidya J, Bhatt R, Patil P, Badwe R, Desai P. Chemotherapy for carcinoma of the esophagus: A comparison of evidence from meta-analyses of randomized trials and of historical control studies. Annals of Oncology 1996; 7(4): 355-359.

7. Urschel JD, Vasan $\mathrm{H}$, Blewett CJ. A meta-analysis of randomized controlled trials that compared neoadjuvant chemotherapy and surgery to surgery alone for resectable esophageal cancer. The American Journal of Surgery 2002; 183(3): 274-279.

8. Hirao M, Ando N, Tsujinaka T, Udagawa $H$, Yano M, Yamana $\mathrm{H}$, et al. Influence of preoperative chemotherapy for advanced thoracic oesophageal squamous cell carcinoma on perioperative complications. British Journal of Surgery 2011; 98(12): 1735-1741.

9. Vogt K, Fenlon D, Rhode S, Malthaner R. Preoperative chemotherapy for resectable thoracic esophageal cancer. Cochrane Database of Systematic Reviews 2006; Issue 3, Art. No.:CD001556.DOI:10.1002/14651858.CD001556.pub2. 10. Eguchi R, Ide $H$, Nakamura $T$, Hayashi K, Ohta M, Okamoto $\mathrm{F}$, et al. Analysis of postoperative complications after esophagectomy for esophageal cancer in patients receiving neoadjuvant therapy. Jpn J Thorac Cardiovasc Surg 1999; 47(11) Nov: 552-8.

11. Waters J, Norman A, Cunningham D, Scarffe J, Webb A, Harper $P$, et al. Long-term survival after epirubicin, cisplatin and fluorouracil for gastric cancer: Results of a randomized trial. British Journal of Cancer 1999; 80(1/2): 269.

12. Cunningham $D$, Allum $W H$, Stenning SP, Thompson $\mathrm{JN}$, Van de Velde CJH, Nicolson $\mathrm{M}$, et al. Perioperative chemotherapy versus surgery alone for resectable gastroesophageal cancer. New England Journal of Medicine 2006; 355(1): 11-20
13. Dikken JL, van de Velde CJH, Coit DG, Shah MA, Verheij M, Cats A. Treatment of resectable gastric cancer. Therapeutic Advances in Gastroenterology 2012; 5(1): 49-69.

14. Epstein SK, Freeman RB, Khayat A, Unterborn JN, Pratt DS , Kaplan MM. Aerobic capacity is associated with 100-day outcome after hepatic transplantation. Liver Transplantation 2004; 10(3): 418-424.

15. Older $P$, Hall A, Hader R. Cardiopulmonary exercise testing as a screening test for perioperative management of major surgery in the elderly*. Chest 1999; 116(2): 355.

16. McCullough PA, Gallagher MJ, dejong AT, Sandberg $\mathrm{KR}$, Trivax JE, Alexander D, et al. Cardiorespiratory fitness and short-term complications after bariatric surgery*. Chest 2006; 130(2): 517.

17. Struthers $R$, Erasmus $P$, Holmes $K$, Warman $P$, Collingwood A \& Sneyd J. Assessing fitness for surgery: A comparison of questionnaire, incremental shuttle walk, and cardiopulmonary exercise testing in general surgical patients. British Journal of Anaesthesia 2008; 101(6): 774.

18. American Thoracic Society \& American College of Chest Physicians. ATS/ACCP statement on cardiopulmonary exercise testing. Am J Respir Crit Care Med 2003; 167: 211-277.

19. Beaver WL, Wasserman K, Whipp BJ. A new method for detecting anaerobic threshold by gas exchange. Journal of Applied Physiology 1986; 60(6): 2020-2027.

20. Smith T, Stonell C, Purkayastha S, Paraskevas P. Cardiopulmonary exercise testing as a risk assessment method in non-cardio-pulmonary surgery: A systematic review. Anaesthesia 2009; 64(8): 883-893(abstract)

21. Weisman IM, Zeballos RJ (eds). An integrative approach to the interpretation of cardiopulmonary exercise testing. 2002 (online)

22. 22-Marulli G, Rea $F$, Nicotra S, Favaretto AG, Perissinotto $\mathrm{E}$, Chizzolini $\mathrm{M}$, et al. Effect of induction chemotherapy on lung function and exercise capacity in patients affected by malignant pleural mesothelioma. European Journal of Cardio-Thoracic Surgery 2010; 37(6): 1464-1469.

23. Vento S, Cainelli F, Temesgen Z. Lung infections after cancer chemotherapy. The Lancet Oncology 2008; 9(10): 982-992.

24. Auerbach $M$, Ballard $H$, Trout JR, Mcllwain $M$, Ackerman $\mathrm{A}$, Bahrain $\mathrm{H}$, et al. Intravenous iron optimizes the response to recombinant human erythropoietin in cancer patients with chemotherapyrelated anemia: A multicenter, open-label, randomized trial. Journal of Clinical Oncology 2004; 22(7): 13011307.

25. Dranitsaris G, Clemons M, Verma S, Lau C \& Vincent M. Chemotherapy-induced anaemia during adjuvant treatment for breast cancer: Development of a prediction model. The Lancet Oncology 2005; 6(11): 856-863.

26. Groopman JE, Itri LM. Chemotherapy-induced anemia in adults: Incidence and treatment. Journal of the National Cancer Institute 1999; 91 (19): 1616-1634.

27. Weiskopf RB, Feiner J, Hopf HW, Viele MK, Watson $\mathrm{JJ}$, Kramer, JH, et al. Oxygen reverses deficits of cognitive function and memory and increased heart rate 
induced by acute severe isovolemic anemia. Anesthesiology 2002; 96(4): 871-877.

28. Bancewicz J, Clark PI, Smith DB, Donnelly, RJ, Fayers $\mathrm{P}$, Weeden $\mathrm{S}$, et al. Surgical resection with or without preoperative chemotherapy in oesophageal cancer: A randomised controlled trial. Lance 2002; 359(9319): 1727-33.

29. Safranek $P$, Sujendran $V$, Baron $R$, Warner $N$, Blesing C, Maynard N. Oxford experience with neoadjuvant chemotherapy and surgical resection for esophageal adenocarcinomas and squamous cell tumors. Diseases of the Esophagus 2007; 21(3): 201206.

30. Hirao M, Ando N, Tsujinaka T, Udagawa H, Yano M, Yamana $\mathrm{H}$, et al. Influence of preoperative chemotherapy for advanced thoracic oesophageal squamous cell carcinoma on perioperative complications. British Journal of Surgery 2011; 98(12): 1735-1741.

31. Hsu F, Lee Y, Lee J, Hsu C, Lin C, Tsai Y, et al. Association of clinical and dosimetric factors with postoperative pulmonary complications in esophageal cancer patients receiving intensity-modulated radiation therapy and concurrent chemotherapy followed by thoracic esophagectomy. Annals of Surgical Oncology 2009; 16(6): 1669-1677.

32. Leo F, Solli P, Veronesi G, Radice D, Floridi A, Gasparri R, et al. Does chemotherapy increase the risk of respiratory complications after pneumonectomy?. J Thorac Cardiovasc Surg 2006; 132: 519-23.

33. Taylor F, Ascione R, Rees K, Narayan P, Angelini G. Socioeconomic deprivation is a predictor of poor postoperative cardiovascular outcomes in patients undergoing coronary artery bypass grafting. Heart 2003; 89(9): 1062-1066.

34. Pollock AM, Vickers N. Deprivation and emergency admissions for cancers of colorectum, lung, and breast in south east England: Ecological study. Bmj 1998; 317(7153): 245-252. 